\title{
Constructivist Dialogue Mapping Analysis of Ant Adaptation
}

\author{
Kit MARTIN, Michael HORN, Uri WILENSKY \\ Northwestern University \\ e-mail:kitmartin@u.northwestern.edu,\{michael-horn,uri\}@northwestern.edu
}

Received: October 2019

\begin{abstract}
This paper introduces constructivist dialogue mapping (CDM), a new type of concept mapping. CDM encodes what people learn during a non-goal directed learning activity. CDM is a practical means to outline the mini theories users fluidly construct as they explore open-ended learning environments. To demonstrate the method, in this paper we use CDM to track how two modelers elaborate understandings during use of a constructionist learning game, Ant Adaptation. Using the method, we show how two users contest and construct their idea of self-organization in ant colonies. The method is rooted in constructionism, constructivism, concept mapping, and conceptual change.
\end{abstract}

Keywords: keyword, constructivism, constructionism, evaluation, qualitative methods, complexity research, agent-based models, concept mapping, conceptual change.

\section{Introduction}

To study open learning activities in a museum, we created a method to encode group learning, through participant dialogue. The approach builds on Piaget's method of clinical interviews, which studied how people talk, and how their speech references the mental models they are using (Piaget, 1926; 1929; 1952). We extended that approach to pictorially represent how people understand complexity. The method creates hierarchical concept maps, we call constructivist dialogue maps, of what people say with a focus on the temporality of when they advance new ideas. The method highlights the possibility that concepts are not stable. The approach, constructivist dialogue mapping (CDM), was innovated to study open-ended, constructionist (Papert, 1986; Papert \& Harel, 1991) learning activity in a museum (Martin, 2018; Martin, Horn \& Wilensky, $2018 ; 2019)$. The approach was developed because of a weakness in evaluation methodologies of open-ended environments (Ochoa \& Worsley, 2016). We argue that a form of deep learning with complex systems models can be documented by using our verbal interactive tool: constructivist dialogue mapping. This tool was developed from con- 
structivist and conceptual change theory. In this paper, we first introduce constructivism, and our definition of concepts. Then, we differentiate CDM from similar methods including concept mapping more broadly, as well as semantic mapping, dialogue, and narrative mapping particularly and provide pictorial examples of those methods. From that point, we narrate how museum studies focus on elaboration to track learning (Leinhardt and Crowley, 1998). In the methods and results sections, we show how CDM can be used to follow how users elaborate their ideas. Then, we will discuss next steps in the process of automating the approach in the discussion section. Finally, we argue CDM allows us to show how it can be used to track theory development during learning in groups, with a computer, and with a facilitator. To begin the discussion, we turn to the theory that underpins each of these visualization methods, constructivism.

\section{Constructivism}

Piaget was a Swiss psychologist who focused on the development of the child's understanding. He presented a notion of knowledge that is constructed. For example, he found that young children, below 3 months old, could not remember where an object was. He would hold his watch on a chain in front of the child, and slowly drag the watch out of sight. When his children were young, they had no "object permanence", and so, when the watch came back, they were surprised, but as they aged he found they could track objects. He concludes that humans "distinguish between these changes of position and changes of state and thus contrast at every moment the thing as it is with the thing as it appears to our sight; again, this dual distinction leads to the permanence characteristic of the object concept" (Piaget, 1952, p. 7). In other words, as the child develops, she becomes able to construct a notion of an object. The list of all objects a child has constructed in this way is her ontology. As a result, knowledge is constructed and a child builds her ontology through action in the world.

To elaborate, consider if the child grew up in a gas cloud in some remote universe. At first, the twirling nebular shapes would appear to have no order, and she would have no ontology for them. Therefore, when a particular eddy returned to the developing child's perception, she would not attach to it any particular permanence because the learner would not have conserved its continuous change into an identified concept. As the learner lived there longer, however, Piaget's theory predicts she would combine the gas cloud eddies into predictable movements based on experience to create concepts of gas cloud objects through the process of assimilation and accommodation. ${ }^{1}$ This

\footnotetext{
${ }^{1}$ One interesting experiment that should be done on this theory is about whether it is that children construct the idea of permanence, or whether it is that they construct the idea of time. That is, at first they experience all time simultaneously and so the object for them is technically in both places, all places, but through experience come to see the object first as here and then there, or in other words in linear time. Basically, do children, only through experience, constructs linear time? This question would have implications for physics, because some of the issues with the unified theory of the universe can be resolved by dropping the notion of time from the equations. According the Julian Barber: "If you try to get your hands-on time, it's always slipping through your fingers people are sure time is there, but they can't get hold of it. My feeling is that they can't get hold of it because it isn't there at all" (Franks, 2011).
} 
process would be conservation: seeing an object in spite of its changing features, or ever-changing atomic arrangement as a continuation of its prior existence. ${ }^{2}$ In this way, all matter is more or less variant, but the child can construct an invariant version out of this directionless, senseless mass, to form a theoretical frame. With this frame, the child can operate on their constructed ontology to make predictions and take action. This is like a biker, who sees a group of people walking, and can bike past them very closely because she can assume they will continue to move the way she has observed them up to now. This prediction of the pedestrians' operation is prone to error, but as a working hypothesis for riding a bike, is close enough. As a result, concepts are fluid. ${ }^{3}$

\section{Concepts}

While there are several perspectives on what a concept is, we take a physicalist theory of mind: a concept is a mental representation the brain employs to mark a class of things, like a nebular swirl or flock of pedestrians, in our world. Concepts are mental representations that allow us to draw appropriate inferences about the type of entities we encounter in our everyday lives (Murphy, 2004). Murphy argues concepts make sense of our lived experience: "Concepts are the glue that holds our mental world together. When we walk into a room, try a new restaurant, go to the supermarket to buy groceries, meet a doctor, or read a story, we must rely on our concepts of the world to help us understand what is happening. We seldom eat the same tomato twice, and we often encounter novel objects, people and situations. Fortunately, even novel things are usually similar to things we already know, often exemplifying a category that we are familiar with" (Murphy, 2004, p. 1). Thus concepts let us see the changing world as consistent, and predictable.

Children construct conceptions. Adults do too. These conceptions have several uses, such as that they can be placed in categories, that aid learners to make inferences. For example, 4- to 7-year-old dinosaur aficionados can generate many appropriate inferences about an unfamiliar dinosaur after they categorize it on the basis of surface, and taxonomic features (Chi \& Koeske, 1983; Gobbo \& Chi, 1986). This categorization allows people to theorize about missing information in a theory (Chi, 2008).

For instance, in Fig. 1 a scientific illustration of Hadrosaurus shows a head. However, there is no fossil record of Hadrosaurus heads. The artists have to extrapolate, deduce, or imagine based on other hadrosaurids. The concept artists construct through experience allows them to infer or deduce the missing information.

\footnotetext{
${ }^{2}$ When learning from an agent based model, this could be described as learning an agents' operators, or rules.

${ }^{3}$ One interesting possibility for constant construction and reconstruction of knowledge is the possibility that there is no memory. In other words, like the original Macintosh, there is no onboard memory, instead knowledge is always reconstructed from the assimilation, or of imposing one's order on the world in the context at hand. One's order then would have to be maintained, but no need for memory, perhaps. This possibility becomes particularly interesting in light of Ackermann (1996) that due to the 3D reconfiguration task required for perspective taking, that some views are harder to reconstruct than others (p. 6).
} 


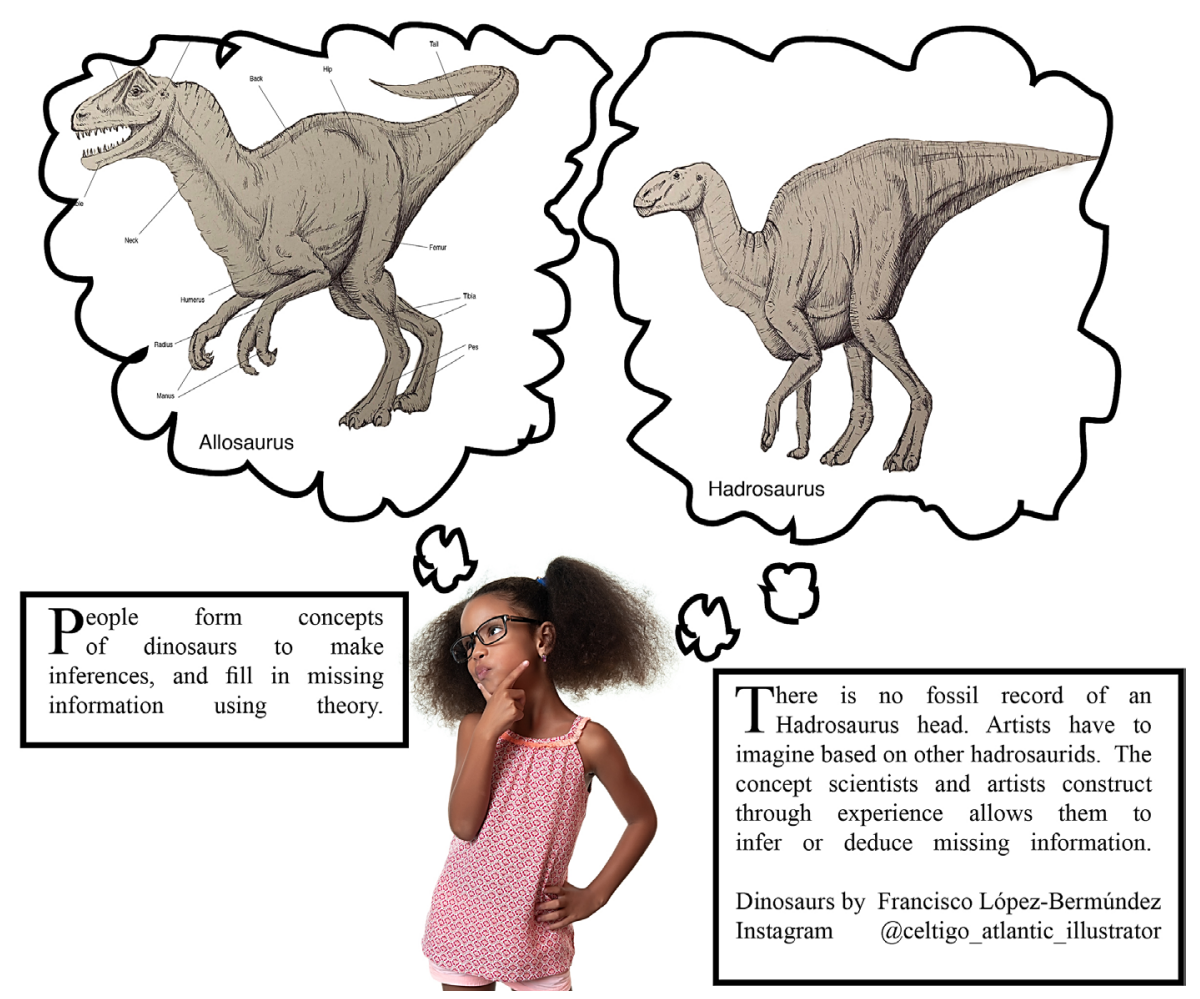

Fig. 1. People form concepts about organisms. They learn the parts of the organism, its functions, and properties, such as color or size. Based on what they know about similar organisms they infer other unknown parts. (Right) Hadrosaurus interpretation. (Left) Allosaurus with taxonomic identification Hadrosaurus and Allosaurus drawn by Francisco López-Bermúndez.

Categorization is a crucial use of concepts in a physicalist view. We identify and assign concepts to the category to which it belongs through categorization (Chi, 2008). Once a concept is categorized it can inherit from where we assign the knowledge. For instance, as long as we know that ants are insects and insects lay eggs, we can infer that ants lay eggs even if we were never told that fact. When a student knows an ant is a kind of insect, she can infer that ants inherit the properties of insects. Categorization of concepts through assignment is powerful because a student can use knowledge of the category to make many inferences and attributions about a novel concept/phenomenon (Medin \& Rips, 2005).

From Aristotle to the 1970s, philosophers argued that concepts have a definitional structure. Concepts defined this way have a list of features, that are both necessary and sufficient to determine membership into a class, i.e., a bachelor is an unmarried man. There are several challenges to this view. For our current project, the biggest challenges are that categories can be "fuzzy", and that there is no psychological evidence for humans using concepts as strict definitions (see Laurence \& Margolis, 1999 for a complete 
accounting of the challenges). Despite this challenge, however, categories remain very useful heuristics for interaction in the world, letting us fill in the missing head of hadrosaurids, and the pedestrian movement for bike riding, among many other daily tasks.

\section{Piagetian Clinical Interviews}

How are concepts formed? In our constructivist view, concepts are conserved ontological entities a person builds through action in the world (Piaget, 1952). So, how do we identify concepts that people hold? Piaget invented a method, the clinical interview, an approach to documenting an open-ended conversation designed to illuminate the way a child thinks or explains particular phenomenon. Even though Piaget widely employed the clinical interview to examine how children construct their knowledge, there is surprisingly little discussion of the method in his work (Posner \& Gertzog, 1982). Piaget elaborated on his data collection method most in the introduction to The Child's Conception of the World (1929), and also in the preface to The Language and Thought of the Child (1926). His method of analysis of the development of cognitive constructions involved observing children as they reason about unusual phenomena that he presented in designed settings. The method involved the following four steps:

(1) Design an activity.

(2) Let the child talk.

(3) Notice the manner in which the thoughts unfold.

(4) Do not just notice the answers the child gives to questions posed, but also follow the child's line of thought.

Piaget argued that "If we follow up each of the child's answers, and then, allowing him to take the lead, induce him to talk more and more freely, we shall gradually establish for every department of intelligence a method of clinical analysis analogous to that which has been adopted by psychiatrists as a means of diagnosis." (emphasis added, Piaget, p. 276 as in Claparéde's preface to Piaget, 1926). This approach is a useful way to follow children's understanding of the world; it focuses on the knowledge, or mental models, children construct during an activity. This process is the process of theory development.

\section{Theory Development}

Theory development is the idea that students' mental models are built out of theories of how the world works, the sum of lessons learned from thinking that builds knowledge. DiSessa and Cobb (2004) argue that from Newton, to Einstein, and Darwin, theories embody generalizations to organize overly abundant data that is subsequently viewed as part of a new theory. In this way, diSessa and Cobb (2004) posit theory as a lens, "teaching us how to see" (p. 4). How we see the world, is the crucial part of these theories since the lenses constructed through experience take actual form. Just as "[t]he world is not just sitting out there waiting to be to be uncovered, but gets progressively shaped 
and transformed through the child's, or the scientist's, personal experience" (Ackermann, 2001), constructivist thought highlights transformation and molding as the work of mental models. These models can form into more stable theories. This transformation happens through conceptual change which we turn to next.

\section{Conceptual Change}

There are at least three circumstances under which a person can learn (Chi, 2008). First, they have no prior knowledge, so they add missing knowledge. Second, the person may have incomplete, but correct knowledge so the learner is filling the gap. Third, the student may need to amend prior knowledge. In this third case we refer to the process of knowledge acquisition as conceptual change (Chi, 2008). Students undergo conceptual change when they perceive a mismatch between previously constructed knowledge and novel experience (Chi, 2008; Posner, Strike, Hewson \& Gertzog, 1982). When the learner experiences contradiction, he/she can reconstruct knowledge structures to account for the novel experience. If the context of learning is aligned with conical scientific knowledge, the resulting structure will more closely resemble scientific knowledge (Chi, 2008; Posner et al, 1982).

There is a connection between observation, contextual knowledge construction, and stable theories. These states convert from each other through conceptual change. When a learner modifies their knowledge, the knowledge-in-pieces framework (KiP) indicates construction happens incrementally over time (sometimes years) (diSessa, 2018). The learner has subtle knowledge infrastructure, that yield conceptual understanding through knowledge structure synthesis. These knowledge structures only exist in context, not as stable structures (Hammer, 1996). Instead context activates specific cognitive building blocks known as phenomenological primitives (p-prims) (diSessa, 1993). These structures can fire differently depending on context, so what may appear as a misconception, may result from a re-ordering of p-prims from different contexts. $\mathrm{KiP}$ indicates that instruction should activate p-prims in the context in which the instructors intends knowledge to be used. Even though knowledge structures are not stable and they operate at different scales (Duit, Treagust, \& Widodo, 2008), some emerge and reinforce to become large, broad, stable knowledge structures stored in memory, like a bikers understanding of pedestrian movement. We call these theories (Darner, 2019). Theories are cohesive mental models that explain causal relationships between several different contexts or phenomena. Our work attempts to track this messy, context dependent path through a type of concept mapping called constructivist dialogue mapping (CDM).

We developed CDM to study learning in an informal environment based on constructivist theory. In constructivist theory, a learner's mental model drives his or her construction of understanding and internal cognitive structures. This process includes accommodation and assimilation (Piaget, 1952), maintaining a balance between stability and change, continuity and diversity, and closure and openness (Ackermann, 2001) 
when exploring the world. For Piaget, children are not just incomplete adults (1952). Their ideas function very well for their current context and as a result, their mind changes through experience. Even though knowledge is contextually bound, so are actions and habits. As Ackermann (2001) said, children's conceptual changes are like those of scientists: they happen through "action-in-the-world" (p. 3) to accommodate for experiences, and most likely through a host of internal cognitive infrastructures. "Knowledge is not merely a commodity to be transmitted, encoded, retained, and re-applied, but a personal experience to be constructed" (Ackermann, 2001, p. 7). Thus, with CDM we hope to track these changes as elaborations of ontologies, as they happen, during knowledge construction to facilitate the study of learning. An example of this sort of learning environment can be found in constructionist microworlds (Edwards, 1995; Papert 1980), or constructionist video games (Holbert \& Wilensky, 2019) where the learning is interwoven into the gameplay.

\section{Elaboration as Learning in Museum Studies}

In Museum Learning as Conversational Elaboration: A Proposal to Capture, Code, and Analyze Talk in Museums, Leinhardt and Crowley propose means to study how learning actually occurs in museums (1998). Their work in museum learning motivates their attempt to solve a core issue: lack of theoretical coherence in the museum learning research. They suggest three problems: first, a need for a learning definition; second, the "univariate" issue where researchers attach a particular indicator, like terms, to a single factor, such as age; third, the museum diversity problem, where research does not span the different types of museums; and finally, the division between quantitative and qualitative research methodologies. From these problems, the authors propose three outcomes, the last of which is important for constructivist dialogue mapping. They argue that their approach will provide a novel, stable, and disseminable methodology to conceptualize, collect, and analyze conversations as a process and as an outcome of learning in the museum context.

After introducing the problems and outlining them, Leinhardt and Crowley (1998) describe a pragmatic approach to study learning in museums: define learning as Conversational Elaboration. For their pragmatic approach and operational definition of learning they chose how visitors elaborate conversations. They focus on conversational elaboration because it is a naturally occurring part of the museum experience while also being a product of the experience.

By elaborations they mean a particular kind of talk that occurs within a group. Conversation is important because it reflects the "inter-twining of social with cultural processes" (White, 1995, p.1). Sociocultural theories of voicing (Rogoff, 1990; Wertsch, 1997) emphasize that inter-twining of voices (in the Bakhtinian sense) is the primary activity through which knowledge is constructed and appropriated across people. In this paper we take this process of studying learning as conversational elaboration, and then use concept mapping to study how these elaborations occur. Next we introduce the different types of concept mapping. 


\section{Concept Mapping}

A concept map is a diagram that depicts relationships between concepts. It is a graphical tool that instructional designers, engineers, technical writers, and others use to organize and structure knowledge. In their overview of qualitative methodology, Miles, Huberman and Saldana (2014) describe concept mapping as useful for qualitative methods. Joseph Novak invented concept maps to assist learners (1983). This theory was based in the philosophical and epistemological origins of Conant (1947), Kuhn (1962), and Toulmin (1972). Concept mapping is a process that focuses on a construct of interest or a topic. The process generates input from one or more participants. As shown in Fig. 2, from it the participant or a researcher produces an interpretable pictorial view (concept map) of their ideas, concepts, and how these are interrelated.

These maps are usually organized hierarchically, and can have the links between them labelled, or not. They can also be organized in other shapes, such as a radiating pattern. There have been varied uses of concept mapping in education over the years. Novak and coauthors' method was used to bring concept mapping into students' hands to better understand science content. This work used concept mapping to improve student learning. Trochim (1989) used concept mapping to guide action in planning and evaluation. Novak (1990) and Kinchin (2014) reconceptualized concept mapping as an educational tool through a wider literature on curriculum development. Jackson and Trochim used concept mapping for analysis of open-ended survey responses, an alternative method to existing code-based and word-based text analysis techniques (2002). There have been many types of concept mapping, including: mind maps, many forms of note-taking, such as Cornell notes, the presentation software Prezi, and repertory grids. Following in this tradition, constructivist dialogue mapping is a type of concept

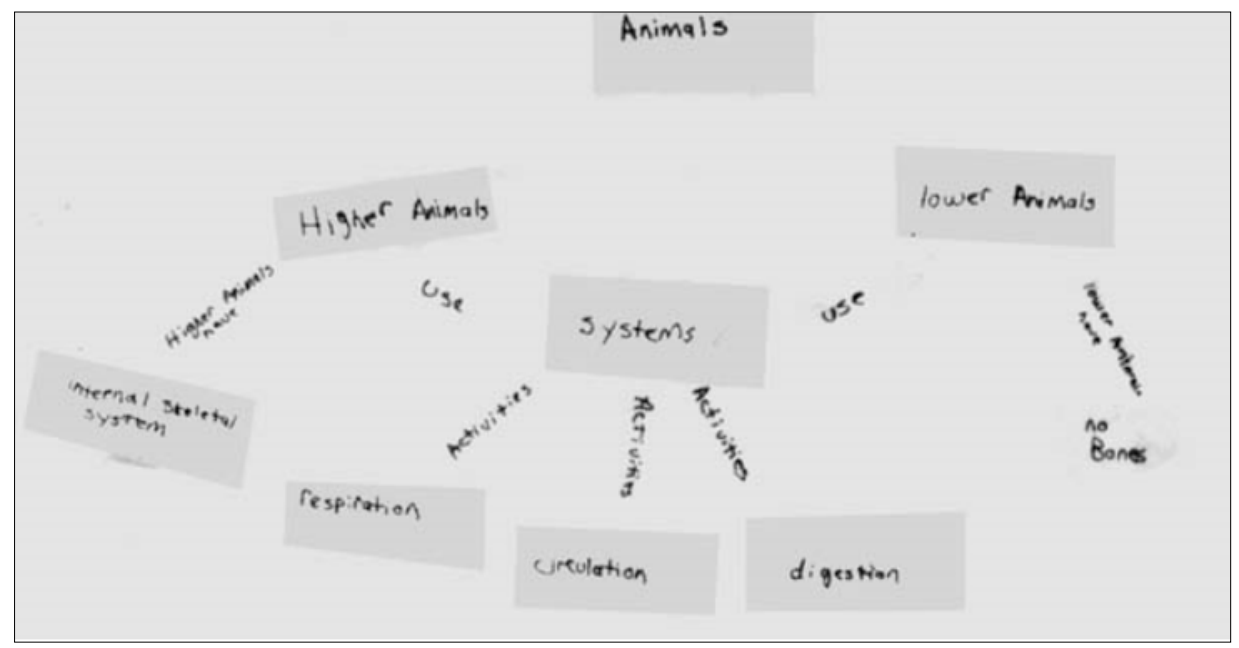

Fig. 2. From Novak, 1983, and example of concept mapping of the concept of animals, differentiating between animals with and without internal skeletal systems. 
mapping meant to track the temporality of when people have ideas during an intervention or interview, and how those ideas elaborate over time. There are several other types of concept mapping that are closely related, which we will introduce next, including semantic, dialogue and narrative maps.

\section{Semantic Mapping}

Semantic mapping is the study regarding the conceptual knowledge, where concepts are represented as a semantic mapping of nodes and their related properties in a network of nodes and links (Anderson, 1976; Collins \& Loftus,1975; Collins \& Quillian, 1969; Norman \& Rumelhart, 1975). As shown in Fig. 3, Attributes of the network structure are assessed by the number of links between nodes, the strength of linkages, and the cohesiveness of the entire collection of concept nodes in semantic memory.

Chi, Hutchinson, and Robin used semantic mapping to represent children's conceptions of dinosaur knowledge (1989). For Chi et al., semantic mapping is the structure of the conceptual knowledge. It is the study of the properties of a representation in a static state. It concerns what a representation is composed of (nodes), how the nodes in the representation are clustered and related to each other, and the cohesiveness of the structure. However, it is not about representational comparison between an adult and a

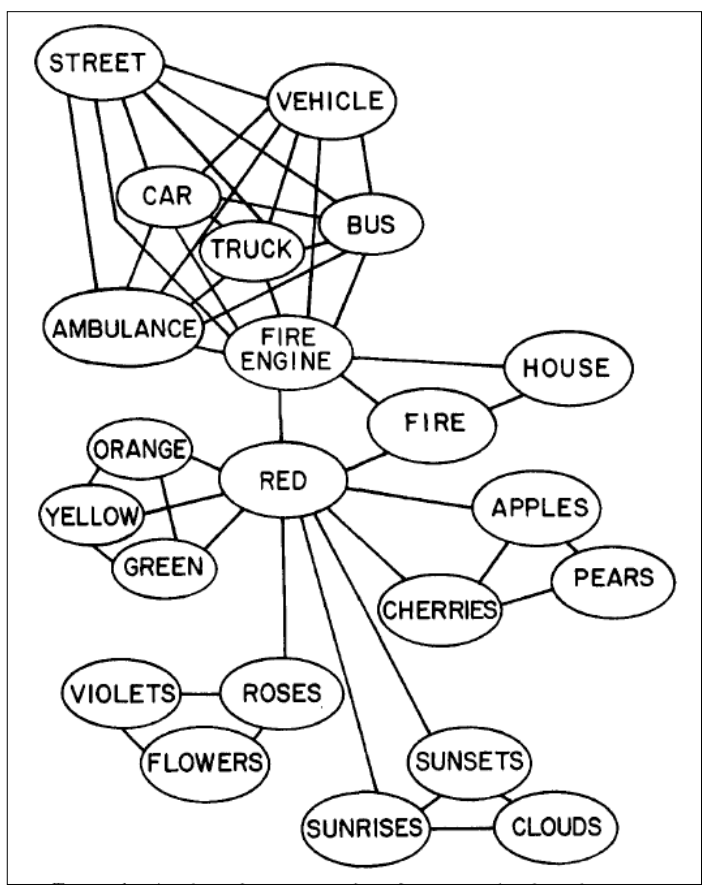

Fig. 3. Adapted from Collins and Loftus (1975), an example of a semantic map of stereotypical map of human memory. 
child, who are believed to have different representations. Likewise, comparison between students of different ages may also be suspect. These hierarchies can be useful when learners employ them to perform categorical reasoning. Categorical reasoning can allow learners to infer that a particular kind of robin, can lay eggs, if they only know that birds lay eggs, because robins are a type of bird (Chi, 2008).

\section{Dialogue and Narrative Mapping}

Concept mapping is related to narrative mapping. Veterans in a social situation, like Alcoholics Anonymous, often use narrative maps to orient, inform and advise newcomers (Pollner \& Stein, 1996). Pollner and Stein describe narrative maps as having several impacts, including:

(1) Affecting recruitment into a social sphere through improving the attractiveness of a situation.

(2) Contributing to socialization and social reproduction by transmitting values.

(3) Shaping action by changing probable activities in an area.

In this way, narrative mapping is part of a process where a social world is talked into being constituted. In other words, narrative mapping is both part of representing a social world, and part of the process of reproducing that social world. Narrative mapping is used to share cultural world resources from current members to new members through a systematic, pictorial representation.

Concept mapping is also related to dialogue mapping. Dialogue maps can provide a visual tool to promote shared understanding between novice (students) and expert

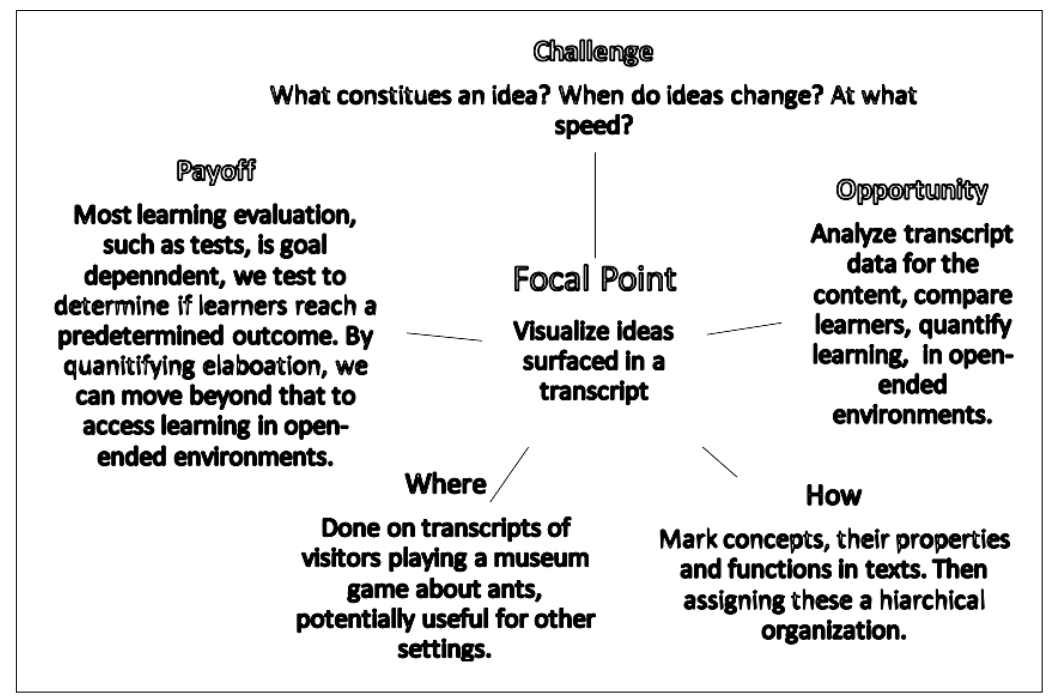

Fig. 4. Adapted from Pollner and Stein (1996) Example of a Narrative Map about Constructivist Dialogue Mapping. 
(teachers) to increase meaningful learning in biology education (Kinchin, 2003). Dialogue mapping can represent and scaffold students' argumentation (Okada \& Shum, 2008). The work to improve student argumentation with dialogue mapping has been assisted by Compendium, a dialogue mapping software (Okada, 2008).

\section{Uniqueness and Differences of the CDM Coding Method}

Constructivist dialogue mapping is a means of producing a pictorial representation of knowledge, but instead of trying to use the representation to improve student learning, it is used to track the instability of knowledge as students learn and associate those changes with learning interventions. We use it to represent players' knowledge states at different times as they develop. CDM is developed to show what learners believe exists (i.e. their ontologies) as they come to understand a complex system modeling game. We believe this method is useful in representing learning in systems where participants elaborate their understandings in interaction with each other, teachers, and technology to form new theories to account for novel experiences. While this method is particularly useful in studying non-goal directed, constructionist learning - where it is difficult to write summative tests, because the learning is not goal directed - constructivist dialogue mapping can be useful for evaluating other learning activities.

The dearth of evaluation methodology for constructionist, open-ended learning environments (Ochoa, Worsley, 2016) motivated our design of CDM. The lack of evaluation can be easily explained by the lack of a learning trace; whereas computer-aided learning systems, if designed for it or not, provide ample data of how the user interacts with the environment. Open-ended people-to-people interactions provide far less data. Because we want to know how participants structure the knowledge they learn in these environments, we developed CDM using constructivist theory, namely - following ideas as they appear, are contested, and fluidly change, based in a knowledge construction view.

\section{Theory: Studying Learning in Informal Learning through Constructivist Dialogue Mapping}

This theory led us to construct a methodological innovation that is useful for the interactions typical of constructionist learning environments. With CDM we track the construction of conserved concepts through the available proxy of change and elaboration of speech. We built on concept maps, methods as they emerged through transcript data focusing on the moment to moment manifestations of ideas. The method is differentiated from age specific representations as semantic maps have been. We do not attempt to use the maps to improve student learning of the connections between material as much of the concept mapping has. Instead, we attempt to track learners moment to moment manifestation of conceptions as they construct them into less variable forms. At this level, these maps represent how a player's speech references the ontological entities they are forming or have formed. We captured these ideas of the understanding players demonstrate 
during play in a hierarchical map. We present concept maps of players elaborating their ideas about agents through observation and interaction that accounts for the changing nature of ideas through activity. Maps visually depict the ideas players share through what they say and how they interact with the game.

We argue that we can research what people conserve (that is, learn through accommodation demonstrated by what they say) by filling in a map with what people say and do during play. Constructivist dialogue mapping allows us to track how people's words and actions indicate learning through short play periods. The more we time stamp when new concepts arise and change through talk, the closer we can track the messy contestation that develops new ontological entities and modifies existing ones. However, these maps, are only a proxy, built from the externally observable action of speech. In this paper, we use transcript data, but the observable data could include log files of their actions, or gestures that describe actions or entities. Importantly, we do not have direct connection to the internal cognitive infrastructure. In other words, the maps are a method to pay close attention to a participant's words, a naturally occurring feature of museum play, while keeping an eye on what it says about her ontology.

The advantage of this approach is we can present the smallest parts of what we observe. For instance, we can note when users first identify an unknown activity, such as "purple line" and then how they build out an understanding of the subprocesses of that task such as "attracts ants" or "fades away." As a result, we read the transcript word by word to see how users construct such operational knowledge on the representations they see. CDM demonstrates learning as concept elaboration over time through the proxy of changes in speech. We will explain the implementation of CDM analysis in the methods section below. First, we will explain our research questions. Then, following Piaget's method, we will explain the design of our unusual activity we used to understand how people come to understand complexity.

\section{Research Questions}

In this paper we use CDM to explore how users make sense of the self-organization of cooperation between ant colonies in competition with each other while they use an agent-based model built in NetLogo (Wilensky, 1999).

We researched how users build knowledge when using the model of ant colony life (Martin \& Wilensky, 2019; Martin, Horn, \& Wilensky, 2019). We were particularly interested in how visitors made sense of the behavior of individual ants in the simulation to in turn reason about aggregate-level outcomes of groups of ants.

Specifically, we asked the following questions:

1. How can we capture visitors' moment to moment sense-making while exploring complex systems notions such as emergence?

2. Can we see evidence that new knowledge structures emerge through game play?

a. How do these knowledge structures shift over time, or remain stable emerging as theories explaining the context? 


\section{Design: Agent Based Modeling Game for a Museum}

To show the environment we evaluated with CDM, we will describe our model/game and discuss the design decisions we took as a result of implementing in the museum.

\section{The Game: Ant Adaptation, Agent-Based Modeling in Museums}

Ant Adaption (Martin \& Wilensky, 2019), the game we use to demonstrate CDM, has been used in studies on schema formation (Martin, Horn \& Wilensky, 2019), and the connection between affect and cognition (Martin, Wang, Bain \& Worsley, 2019). In this paper we used it to collect data and use CDM to analyze that data to demonstrate constructivist dialogue mapping. In order to provide context for our analysis, we describe the game below.

In the game we created, Ant Adaptation, there is a fully functioning agent-based model underneath. Ants go out to collect food and return to the nest. As they return to the nest, ants lay down a pink pheromone that attracts others nearby. Other ants walk toward the strongest chemical smell, which in most cases is where the first ant just passed. When ants find a flower, their food source, they return, lay down a pheromone trail, and thus construct and reinforce pink trails. This creates an emergent feedback loop that routes more and more ants to successful sites of forage. As the ants exhaust a food source, they must find new locations, and thus repeat a cycle. When two or more ants of opposing colonies encounter each other, they fight or scare each other away, also leaving chemicals that attract more ants. For the winner, this works to protect the food source from competing colonies. The ant queen reproduces when the ants in her colony collect enough food. The player interacts with this complex system by adding pheromone trails that the ants follow, as well as adding sources of food to the system, thus changing the amount and distribution of food in the game. Through interacting with the system, students form a functional understanding of the ants and their mechanisms of action (i.e. agents and their rules) in the model.

This design scaffolds experimentation. Players must simultaneously make choices. As shown in Fig. 5D, players can touch the screen to add pheromone the ants will follow. At the flick of a switch, they can add more flowers anywhere they like in the game. Lastly, they can choose to apply vinegar, which erases trails. Erasing trails was used by some game players (like Thomas discussed below) to get ants out of a feedback loop that was leading them nowhere (a local optima). For players to achieve their goals in the competitive environment, they need to understand the emergent consequences of simple ant behavior.

Players can decide how big and aggressive ants are. When the size of ants increases, they become slightly faster and stronger in a fight. Each increase in size/level adds up. At the highest levels, the ants are thirteen times stronger. When players make their ants more aggressive, it increases the radius in which ants detect opposing ants and thus the probability that they will attack. Increasing either the size or the aggressiveness also increases how much food is required to raise an ant, so the largest ant requires thirteen 


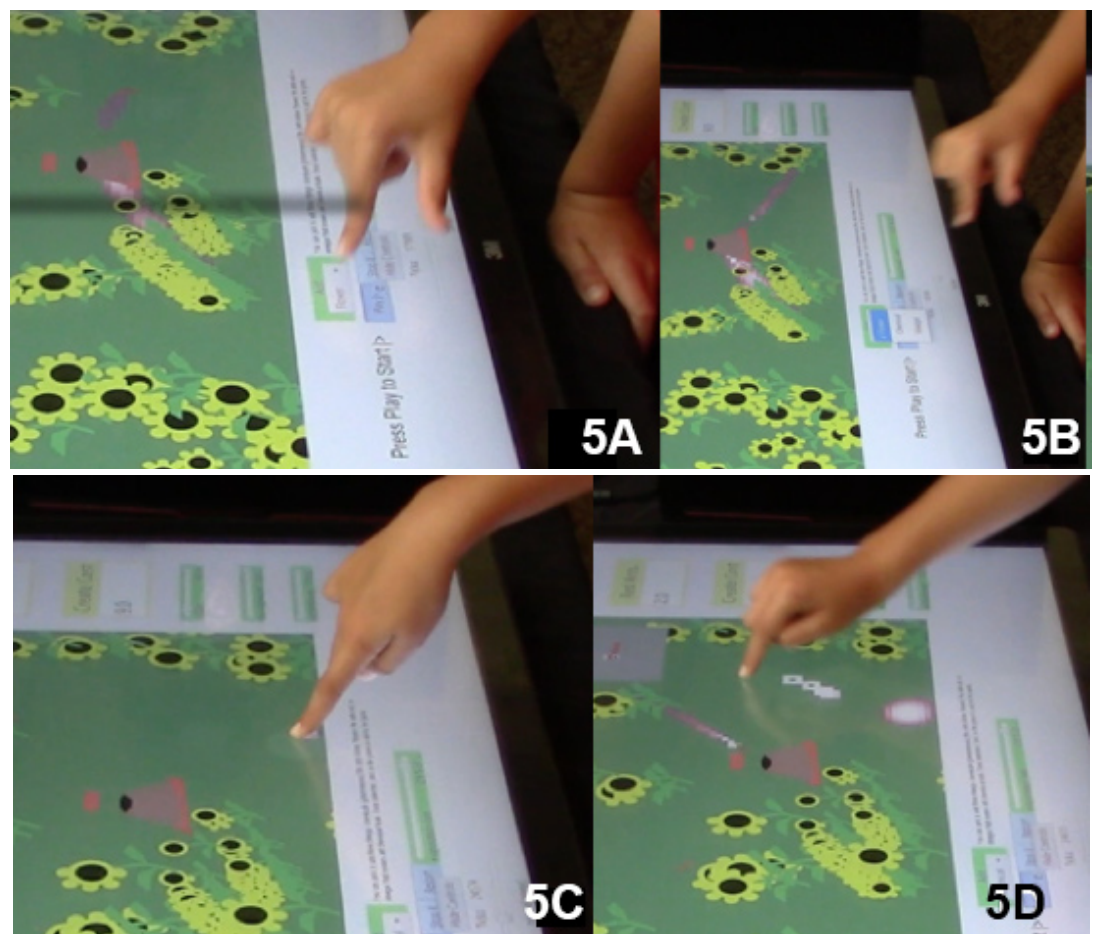

Fig. 5. John selects to add chemical (A) experiments with the touch user interface (B-C) and then lays down his first pheromone trail (D).

times as much food to feed to adulthood. This gamification impacts how much food ants must collect to make a new baby ant. Increases in either of these parameters reduces the expected population of the colony, though it increases their likelihood of fighting and winning through emergent interactions of parameters (size and aggressiveness) and agent actions (collecting food, leaving trails, and fighting).

This sets up the main action of the game as a series of strategic choices: to decide whether to passively collect food, thereby increasing the population, or, to go on the warpath where big, aggressive ants conquer their opponents. Either method of play could lead to high populations or the elimination of the opponent through better control of food resources. After learning about the consequences of strategic choices through gameplay, players strategize by increasing ants' size, aggressiveness, or both. This might lead them to win the game by annihilating the other group's ant colony. However, bigger and/or more aggressive ants consume more food to reproduce, and potentially reduce the colony's population size. Thus, a player might strategize by adding more flowers and pheromone tracks around the colony to help the larger ants survive. This learning and strategy cycle interweaves the learning into the gameplay.

We built the game to be engaging while using the literature of designing digital interactives for museums to have four affordances and two objectives (Martin, Horn, and Wilensky, 2019). The game has four affordances that support two learning objec- 
tives. In Ant Adaptation, playing with parameters allows the player to (1) construct their colony in competition with an opponent, (2) share strategies through comparison, (3) discuss what is happening through observer scaffolding such as parents' intervention, or interaction between players, including taunts, and (4) learn about the emergent impacts of colony behavior arising from individual ant behavior in a complex system game. This approach allows visitors to learn (1) the impacts of adaptation on ant colony life, and (2) how attractants such as pheromones work in ants' self-organization.

\section{Method: Constructivist Dialogue Mapping}

CDM presents learning as concept elaboration (Leinhardt \& Crowley, 1998) through transcript analysis. We innovate the method to record the agents, properties and actions that users notice in two learning environments. We conducted two treatments: (1) 6 , hour-long individual clinical interviews in a lab setting; and (2) 38, approximately 4-20minute group interviews in a natural history museum.

\section{Treatment One}

In the clinical interviews we conducted a semi-structured interview protocol. This was administered while people discussed their understanding of Ant Adaption. In treatment one, there were 6 participants (50\% White, $16.16 \%$ Black, $16.16 \%$ Asian, $16.16 \%$ Latinx) being 50\% male and 50\% female. We recorded audio and video of participants, transcribed the data from the audio, and analyzed both the media to construct CDMs.

\section{Treatment Two}

In the second treatment, participants were sampled over a six-day period, attracting 114 museum visitors in 38 groups (87\% White, 4\% Black, 5\% Asian, 3\% Latinx). This contrasts with the museum-wide attendance demographics of $70 \%$ White (difference of $+16.61 \%$ points), $5 \%$ Black, (difference of $-0.54 \%$ points) and $14 \%$ Latinx (difference of $-11.32 \%$ points). Of the players, 60 were male $(51.57 \%)$ and $54(48.43 \%)$ were female. Players ranged in age from 2 to 55, with the age distribution skewed to lower ages. The average length of time people played was 387 seconds, as opposed to a museum-wide average interaction time with digital interactives of 105 seconds (as reported by internal museum evaluations). In treatment two, we conducted a pre-post survey, and video and audio recorded the play. From the audio we transcribed the data, and analyzed both media to construct CDMs.

\section{Which Changes Are Conceptual Change}

Leinhardt and Crowley (1998)'s approach particularly looks at four process that groups will undertake. If there is learning, after an interaction with an exhibit, a coherent conversation group (CCG) will:

1. Refer to more items.

2. Include greater detail about those items. 
3. Synthesize elements to elements from their prior knowledge.

4. Increase the level of analysis of the phenomena that they discuss.

This approach moves away from focusing on the amount of talk or types of talk while building a strong foundation between amount, type and the process of learning. As a result of this review, Leinhardt and Crowley suggest to investigate how conversation as a socially mediating activity acts as a process and an outcome of museum learning experiences.

In the end, the methods of collection and analysis offered by Leinhardt and Crowley, (1998) are interesting, but they are not sufficient. With text capture, and direction capture we can measure the learning much more fully than Leinhardt and Crowley did.

\section{Constructing Constructivist Dialogue Mapping}

As shown in Fig. 6, CDM tracks the nouns that players mention during play with a system (such as ants); the adjectives that modify those nouns, such as "six-legged" (6b); and the verbs players use to describe those nouns' actions, such as "follows trails" (6d). To gather the transcripts, that we analyzed for CDM, we applied a mixed methods approach to the observations (Clampet-Lundquist, Edin, Kling \& Duncan, 2011).

We coded the transcripts by reading them. When we read a noun, we added a row to our matrix. We then recorded the interview session, noting whether this interaction was during the pre-interview, gameplay, or post-interview, noting who spoke, what time they spoke, the question being answered, the exact quote of the response, and the node label we coded the quote as. Finally, we recorded what parent box it modified and counted the node's depth in the hierarchy. For example, in Table 1: Kit asks Briana if she has ever noticed anything about ants. She responds, "They carry fifty times their weight?" As shown in Fig. 6b, we would code this as a two-level deep hierarchy: Level 1-Ants and Level 2-Carry 50X weight.

To answer our second research question - How can we capture visitors ' moment to moment sense making while exploring complex systems notions such as emergencewe deployed this method to construct maps of ontological entities in the game (i.e., agents), their actions, and properties as described by players. The maps were constructed by building a hierarchical map of players' utterances using the coding method shown in Fig. 6 and Table 1, before, during, and after play. The coders proceeded through the transcript utterance by utterance. When an entity was named, such as "ant", the coder added a box. When other entities were named - such as the property "six-legged" or action "carries a lot of weight" - coders determined what that concept modified. If, as in Table 1, they modified "ant" unambiguously, then the coders added a subordinated box below ant. In our coding during treatment two, we broke the transcript into a preinterview, a game play portion, and a post-interview. We analyzed the change in how players thought about the actions ants take, and the functions of those actions. In Fig. 6, we would look at how the person describes ants as six-legged (Fig. 6a), six-legged 


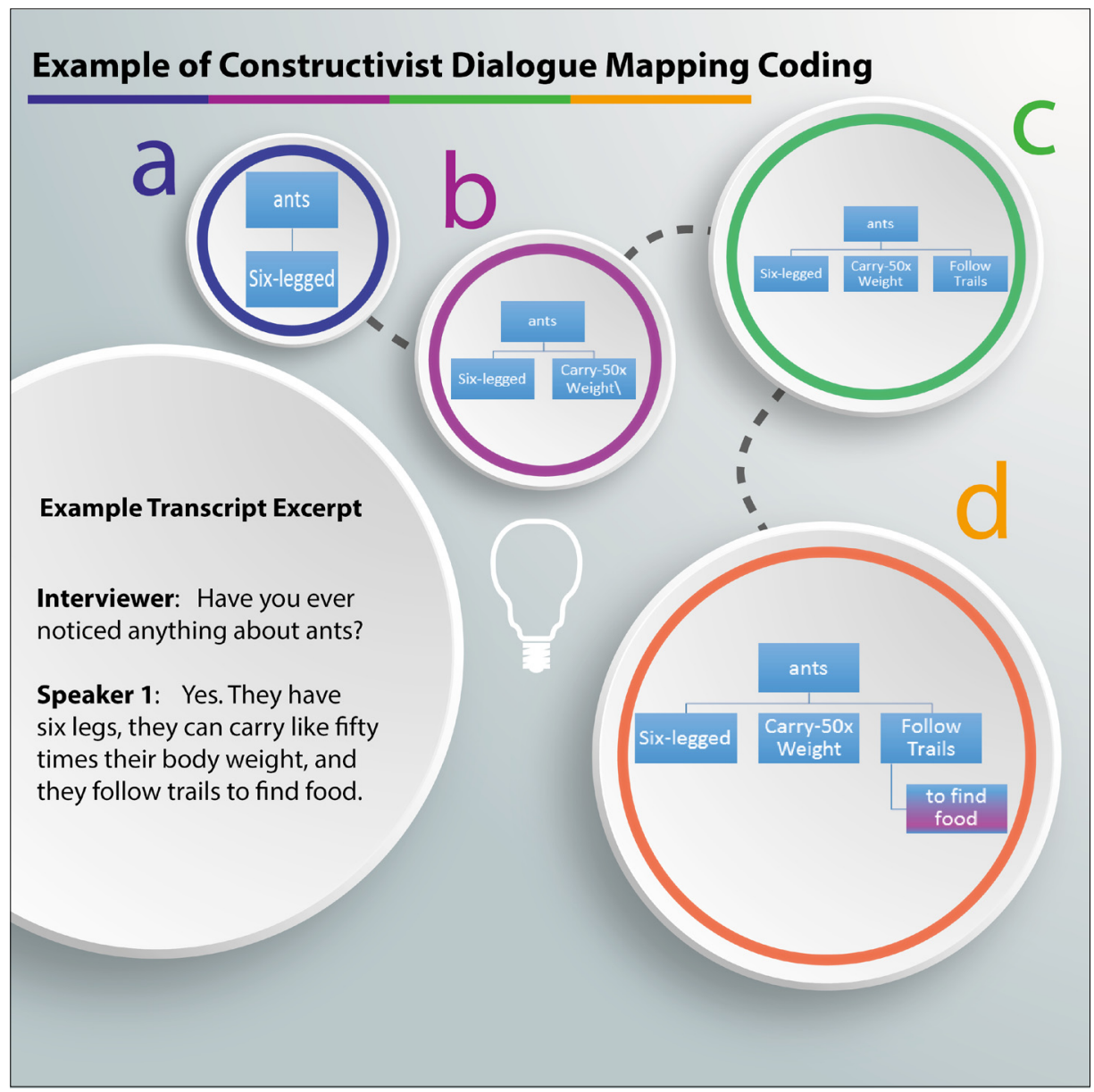

Fig. 6. Constructivist dialogue mapping provides a simple interactive way of mapping ontological entities, to their functions as demonstrated by players in short interactions.

Table 1

Coding Scheme for Constructivist Dialogue Mapping. Captures where in the interview knowledge was mentioned, and by who, allowing for analysis of the development of knowledge as it is mentioned

\begin{tabular}{|c|c|c|c|c|c|c|c|c|c|}
\hline $\begin{array}{l}\text { Session } \\
\text { ID }\end{array}$ & Time & $\begin{array}{l}\text { Interaction } \\
\text { Type }\end{array}$ & $\begin{array}{l}\text { Sequ- } \\
\text { ence }\end{array}$ & Speaker & Question & Quote & Node & $\begin{array}{l}\text { Parent } \\
\text { Node }\end{array}$ & $\begin{array}{l}\text { Node } \\
\text { Depth }\end{array}$ \\
\hline 3 & $10: 23$ & $\begin{array}{l}\text { Pre- } \\
\text { Interview }\end{array}$ & 0 & Kit & $\begin{array}{l}\text { "Have You } \\
\text { ever noticed } \\
\text { anything about } \\
\text { ants?" }\end{array}$ & & Ant & & 1 \\
\hline 3 & $10: 33$ & $\begin{array}{l}\text { Pre- } \\
\text { Interview }\end{array}$ & 1 & Briana & $\begin{array}{l}\text { "Have You } \\
\text { ever noticed } \\
\text { anything about } \\
\text { ants?" }\end{array}$ & $\begin{array}{l}\text { iAbout ants? } \\
\text { They carry } \\
\text { fifty times } \\
\text { their weight?î }\end{array}$ & $\begin{array}{l}\text { Carry-Six } \\
\text { times their } \\
\text { weight }\end{array}$ & Ant & 2 \\
\hline
\end{tabular}


creatures that carry 50x their weight and follow trails to find food (Fig. 6d). When these entities, actions, and properties change over time is our measure of learning during the intervention.

In treatment two, we color code change in ontological maps over time so we can visually compare learning. When we add a box between the first sample and the second, we color it red. When we remove a box, either because the visitor has stopped mentioning the idea, or has explicitly contradicted themselves, we color the box grey and strike through the text. When it is not clear if the item was there previously, or if it has gone away, we leave them blue. We present two times scales of analysis in the results, showing both the micro and macro changes. In treatment one, we analyzed the concepts participants put forward as they emerged during the protocol and highlight the conflicting notions participants demonstrate.

The resulting representations have three affordances:

1. Evaluators can count the number of entities players notice during gameplay. We can note the number of actions and properties they ascribe to those entities. The counting proceeds by adding the total number of node depth 1 items, then the total number of actions, and then properties users ascribe to that entity.

2. If surveyors sample visitors at more than one point in time, we can track the changes over time of both the number of entities they notice and the number of actions and properties player's use to describe the agents' actions and properties.

3. Researchers can track the conflicting and changing nature of knowledge as demonstrated through the maps.

In an open-ended environment people learn what is allowed in a system, rather than memorizing. Therefore, we used mapping instead of measuring change through responses in a more rigid classroom-style questioning.

"In this picture, the participants are active theorizers. They gather new evidence and devise methods to test their theories. Instead of accepting classifications as given, they see these classifications as provisional theories that are constantly reassessed and reconstructed in light of the dialogue between theory and evidence" (Wilensky \& Reisman, 2006, p. 172). We sought to capture how talk changes based on interactions with the learning environment of Ant Adaptation. We propose that learning is demonstrated by what students added to their discussions while playing. This elaboration in their discussion is demonstrated by coding their interactions with CDM.

\section{Results}

During the activity, users learned about complex systems. We tracked this elaboration of concepts through CDM. We test CDM in two treatments: (1) in a clinical interview with Rebecca, where she develops ideas about ants during an hour-long interview, and (2) with a group of students who played Ant Adaptation in a museum. These samples were chosen because they demonstrated key aspects of constructivist dialogue mapping as a tool. 


\section{Dialogue Elaboration through Play}

First, we present two demonstrative cases of the 44 interviews conducted with a complex system model of ants (Martin \& Wilensky, 2019) to illustrate how we use CDM to study learning as elaboration.

We coded two people engaged with Ant Adaptation. First, conducted under treatment one, we examined how an Asian woman, Rebecca (all names changed for anonymity), age 28, engaged. Second, we examined a group from treatment two, noting how Thomas, age 7, engaged in group of three other White youth: Ed, age 12; Mary, age 9; and Sam, age 6. The five players presented were more engaged than the average player of Ant Adaption, along several measures: All of them touched the screen, and smiled during play (showed their teeth while seperating their lips either with or without audible laughter), and all worked to maximize their ants' colony population count (Stating that they wanted to maximize their population during play). This is in contrast to the wider sample where $81 \%$ (92 people) touched the screen, $43 \%$ (49 people) smiled during play, and $41 \%$ (46 people) tried to maximize their colonies' population during play. As there was no guidance on the goal of the interaction, it was surprising that so many of the groups chose maximizing their population of ants as their primary goal. In the openended environment, they could just have easily drawn smiley faces with their fingers or planted a flower garden. Perhaps this goal was so popular in the museum because of the competive arrangement of the exhibit. Yet this also occurred in the clinical interviews. For the clinical interviews (which lacked this arrangement), we are not sure why this happened. More study is required to investigate this outcome, which will be performed in the analysis of the remaining groups in future work.

\section{Treatment One, Assimilation of Pheromones:}

\section{Constructing a Trail Theory from Watching Digital Ants}

Sitting on a couch in a quiet room, with just the interviewer and Rebecca we began the interview. We started the interview by telling Rebecca we were interested in ants. We

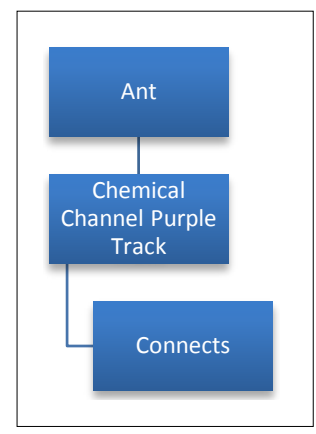

Fig. 7. Rebecca identifies a purple track process that ants do. 
asked her if she would mind if we recorded her while we asked her some questions. After consenting to be interviewed we asked about her prior ant knowledge from which it was clear she had minimal understanding of ants, or ant colonies. We then coded the interview with CDM to observe moments of cognitive change, or synthesis. This coding is the beginning of making a little mental machine we can use to dissect with transcript analysis. The current process produces maps from transcripts, which are useful as summaries, but the exact connection between cognitive change and the maps is still amorphous. In other words, we have only just stepped into this nebula, and are still finding names for what we are seeing.

In this proto state, to demonstrate CDM we present the portions of the interview where Rebecca constructs an understanding of the pink lines (pheromone trails), what they do, and how they affect ant colonies in three parts. This construction occurs through addition of ontological identities, such as trails, and ant queens, and synthesis of competing ideas. Over time, it becomes clear she holds two separate notions of the same concept, and then merges them. This is an example of concept formation, instability of concepts, inference from theory, and the conservation of a new ontological entity. This is also an example of deep learning as she adds functions and properties onto her idea of ants, and pheromone trails. In the first minute, she presents her confusion over "purple lines." Here she identifies an action she observes, but has not yet conserved into a concept she can operate with. At first she identifies a mysterious, unknown object. This is pre-conservation:

Rebecca: I'm looking at... I'm looking at the red one in the middle. The red ant. What are they doing here? What's that line for?

Interviewer: What do you think?...

Rebecca: $\quad$ This purple line. Look there is another one. Its dropping here. The red ants are dropping. Hold on, let me put this. What's that? Is that channel? Chemical Channel?

Interviewer: What do you mean?

Rebecca: Like when it releases chemical it left-it's a new colony here-it left a purple track. You see just the purple track you see just purple track disappeared a couple of minutes ago when I ask you and, you asked me 'what do I think'. I thought it was just something like a track. A chemical. Yeah.

Rebecca first sees a purple line coming out of a red colony in the middle of the screen and wonders what it is and what is it for. She sees that ants leave it. At this time, Rebecca's confusion with the purple lines first comes up. As seen in Fig. 7, this identification helps her identify a novel process: "Chemical channel/purple track" that ants do. She immediately ties chemicals to the lines but does not seem to put forward why. In other words, she creates an ontological entity to see the game, but has not added many functions or properties to it yet. She attempts to test her ideas. When we probed her for what she thinks the track does - that is what functions it has - she is seeing the connective property of chemical tracks and then one of the potential impacts of that track. In other 
words, she starts to hypothesize about the function of the line. This is the beginning of a conceptual change where she begins to elaborate her understanding through dynamic interaction with the complex system game. We then wanted to know what she thinks it does, and so ask her. She suggests it connects ants:

Interviewer: What do you mean by a track or a channel? What's the channel or the track do?

Rebecca: It connects these two groups together. This chemical.

Interviewer: Okay. It connects them how?

Rebecca: $\quad$ Look they are connecting. And I guess it's not a good thing because it looks like it's a war.

Interviewer: It's a what?

Rebecca: It's a war.

Interviewer: Where's the war?

Rebecca: Here. [Points at the top right of screen where ants from both colonies are massing]

Interviewer: How do you guess that?

Rebecca: Oh, there's no turning back as there's no turning around that red ants back there. They are entering into the black ant colony. And the number of escape, hold on. The reason it is not dropping because there's flowers. So far. Look they keep going to this black ant colony. And I don't know what they're doing are they trying to steal that food? They are stealing food. They are stealing food. Come on! [talking to the ants] You have food here [points at the screen where flowers are].

This is an example of elaboration of her concept. After initially realizing she does not know what the chemical does, through testing she constructs the idea that channels "connect" ants and sees that this can cause "war" of some sort. The war seems to be an example of prior knowledge about conflict. But she also begins conceptualizing "war" as a result of self-organization of ants connected by channels. After answering other questions, she brought the topic up again, confirming that she had kept thinking about it. She at first was confused, but then the interviewer provided her with some declarative knowledge, that pheromones are a type of chemical which connects ants together. She then takes that information and identifies a new function, but does not merge it right away with her previously constructed idea of chemical channels. Instead she holds to categories of activities ants do. In other words, she has constructed two models, one to do with chemicals, and one based on the declarative knowledge provided. About pheromones she has no reason to think they are the same concept from her previous experiences, as in the real-world pheromones are invisible, and these purple lines are quite visible. As a result, she holds two concepts at once:

Rebecca: I'm kind of confused by the purple zone. So, this purple zone is something like this chemical released?

Interviewer: Why do you think that? 
Rebecca: So, let's see. Ijust created this chemical channel.

Rebecca: If this flower needs to be on this chemical to help. I'm gonna see. It doesn't eat them. Go eat them. Why don't they eat them? It's weird. It doesn't work that way. I should just make circles around the corners, so they know there are chemicals.

Interviewer: Could you press pause? I have a long question to ask you.

Interviewer: So, E.O Wilson, a big ant researcher, discovered pheromones. He realized that they are like perfume placed on the ground to mark the food or when they encounter an enemy to encourage other ants in the colony to come over and fight with the enemy. After hearing about Wilson's findings how might you adjust your explanation of how these ants are getting food?

With the probe, we wanted to see what the introduction of declarative knowledge did to the understanding of the model. At first, she took the declarative information in, and made valid predictions based on it. But interestingly, at first, she did not map this onto the purple lines she's been confused by. Instead of conceptual change she held two concepts at the same time, as shown in Fig. 8.

Rebecca: Well when one ant senses the food around them they will leave this pheromone to other ants. And so, they can be attracted to this, to the flowers.

Interviewer: Ok. So, what in here do you think is the pheromones?

Rebecca: I guess somewhere near this colony. Uhh. No no actually here maybe here.

Interviewer: Here what?

Rebecca: Here when there is a group of [ants]. There is a huge group of ants.

Interviewer: $O k$.

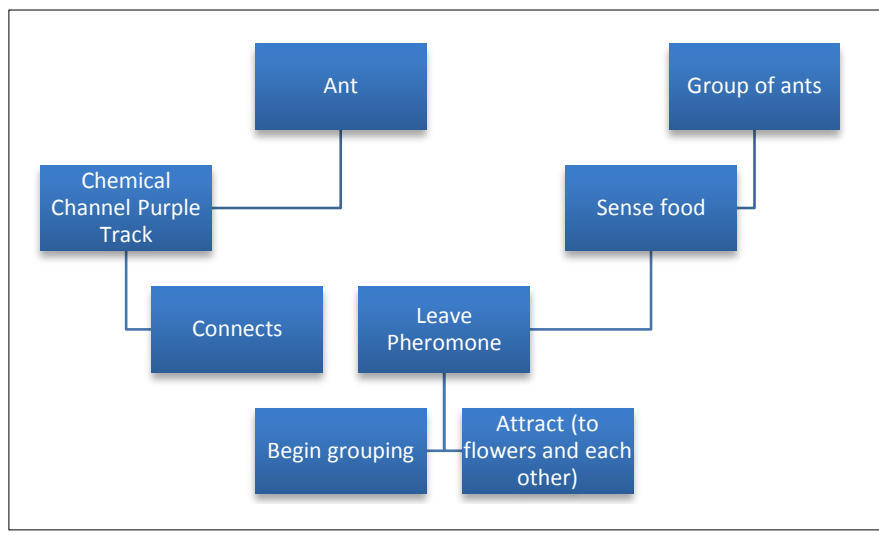

Fig. 8. Rebecca sees two separate processes, Pheromones and Chemical. 
Rebecca: Does that make sense?

Interviewer: So, you think this this what wouldn't call it this perfume placed on the ground. Do you think that's just where ants are?

Rebecca: Yeah.

Rebecca: $\quad$ Because where there are ants there are pheromones are a way for them to communicate. If there is somewhere like this [points at blank area] ... this, there's no ants. How do we know there are pheromones? There are not ants so there is no pheromone. This is a chemical released by them. So, I guess that the denser a group of ants are, the more communication they will have to with each other, the more pheromone there will be. That's my that's my guess.

Interviewer: That's your guess. Does that change your way you're explaining how they get food?

Rebecca: Can I say I don't know.

Interviewer: Yeah that's fine.

Rebecca: I don't really know.

At this point, Rebecca has two ideas. As shown in Fig. 8, first there is a purple chemical trail left by an ant, which connects ants. Second, she also imagines a mechanism called "pheromones" learned from the researcher, that ants leave, and that attracts more ants as communication gets denser. Interestingly, this sort of situation may come up in many learning environments, where a learner may have her idea constructed from her own experience in the world, and a set of declarative facts. For Rebecca, these two are models she is simultaneously using to explain the simulation. Shortly, she will conserve the two ideas into one through concept formation, inferring missing information from that concept. At this point in the interview, she uses these dual models to answer some questions about how congestions and disease work in ant colonies and applies both ideas fairly differently, demonstrating the robustness of the two models. After seeing it employed, we finally ask her if she can also see pheromones in the model. At that point, she seems to assimilate by merging the two understandings into one ideas:

Interviewer: Can you see the pheromones in this model?

Rebecca: OH! Is this purple line pheromone?!

Interviewer: What do you think?

Rebecca: Hold on, let me just... cannot see clearly. My view is blocked by these flowers. [She examines the model for 16 seconds.]

Rebecca: Oh, I see. Did you notice that? You obviously noticed that.

Rebecca conserves her two understandings and then double checks her Eureka moment:

Interviewer: Noticed what?

Rebecca: $\quad$ The denser the ants are the more ants, the more it is, you see that ants are grouping here and the surrounding background color is like, bright 
white. Because they are releasing a lot of pheromones. A single ant just leaves this pheromones trails, like these purple trails, but when they are grouping together there's like a powerball.

Interviewer: Like a what?

We were not sure what a powerball was, but assumed she meant a massing and wanted to be clearer on that. She clarifies that it means a lot of ants grouping together.

Rebecca: It's a powerball.

Interviewer: $O k$.

Rebecca: $\quad$ There's a very strong powerball which means a lot of ants are releasing the pheromone chemicals together.

Interviewer: So, what does that do?

Rebecca: Now? I don't know what they are doing. There are just I guess, I know what you mean, look you see these bright white places. that means they are releasing chemicals aggressively. They are releasing chemicals to let maybe friends their team players know there are food. 'Come here.'

Interviewer: So why is the pink disappearing?

Rebecca: Disappearing? Maybe there are no food for them.

\section{Like here.}

Rebecca: Because it's a chemical. It disappears.

Interviewer: What do you mean?

Rebecca: $\quad Y o u$ release chemicals and chemicals kind of spread in the air.

As seen in Fig. 9, Rebecca assimilates the two branches of her understanding into one, forming a concept. This is an example of conceptual change. She no longer holds two separate ideas, one from declarative knowledge and one from experience, but instead holds one model of how pheromones lead to agglomerations of ants that help them self-organize to solve daily tasks. This is also an example of deep learning, where she forms a process understanding. Then she adds a beginning state and an ending state to the pheromones process. She also maps the action onto the coloration of the ground process, seeing that whiter increases grouping resulting in a "powerball" where white means higher concentrations of ants, and purple means lower concentrations of ants. This is an example of forming a theory to better see the world. It also is an example of discovering the meaning of representation through both declarative knowledge and working with a computer- based model. Finally, she also invokes prior knowledge in her theory to predict the chemical dissipate in air subprocess when released. It's a break through moment. After joining these processes together, she makes several predictions with her newly conserved theory helping her see the world in a new way:

Rebecca: Now I know.

Interviewer: What do you know?

Rebecca: This chemical maybe [sends] the wrong messages. 


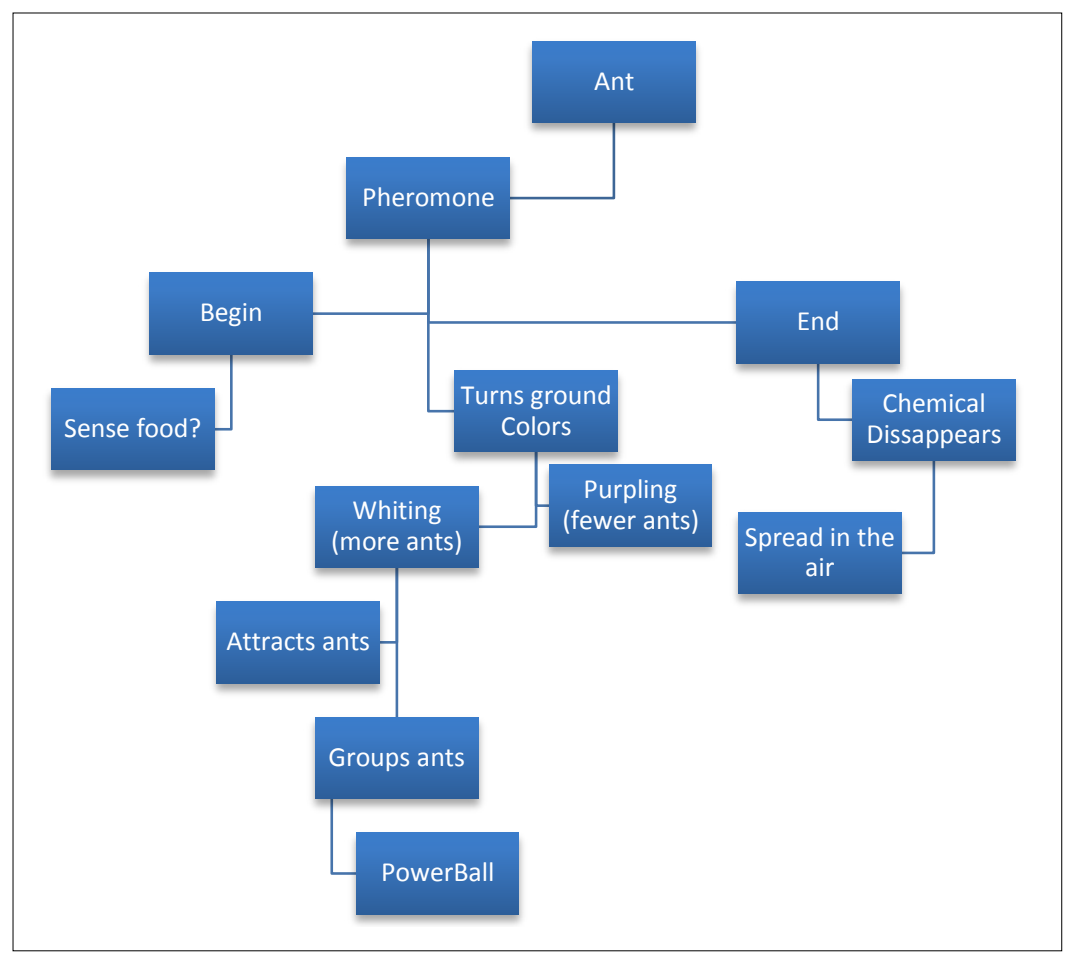

Fig. 9. Rebecca accommodates her observation of chemical trails with her declarative knowledge about pheromone trails. She then adds beginnings and endings to her processes.

Rebecca: Oh, I see. The stronger the messages the stronger this is, the more ants will be attracted to this place.... Such a good game, I love it.

Rebecca: We're kind of helping them to release the pheromones. Is that right, about this chemical?

Interviewer: How would you know that?

Rebecca: Because there is a chemical option.

Interviewer: And how do you know that's how you do. Why did you guess that?

Rebecca: Why do I get that?

Rebecca: Yeah.

Rebecca: Because once I press this button they are kind of attracted by this track, this pheromone track.

At the end of the interview, Rebecca has constructed a model that the purple tracks are called pheromone tracks, they are laid down by ants, and help the ants organize for food gathering and war. At this point Rebecca has assimilated the two understandings, observed and declarative, to form a new theory of how ants communicate. This new theory led to conceptual change through play with a simulation that she can use to predict the ants movements, and trail placement: 
Interviewer: Do you know anything now, after playing this game that you didn't know before?

Rebeca: Yeah. Like this pheromone. Chemical I was confused. Like creating channels for them. You know actually not, its leaving chemicals for them to follow.

Rebecca went from visual confusion to a theory. She now mapped a system of communication onto what was once visually confusing through assimilating while using a simulation through a process of conceptual change.

As a caveat, from this interview there are two key factors we do not know: (1) the length of time this new conception will last. Without reinforcement, or better yet, a delay study to query how long the idea persists, we can say nothing about the durability of these ideas. Worryingly, because they arose quickly, they may fade quickly. And (2) we should consider the situationally contingent nature of the learning, it happened in interaction with a model, and an interviewer. If other researchers use the method, some thought should be given if such situational constraints should be inserted while coding with CDM.

\section{Rebecca's Agent-Based Knowledge Construction}

To answer our second research question - can we see evidence that new knowledge structures emerge through gameplay and how these structures shift through time - we examined how Rebecca builds her knowledge about ants. We answer this by following through her elaborations during the play. As shown above, Rebecca first identifies a phenomenon she does not understand, namely, purple tracks. Then through observation, she makes a conclusion that that phenomenon attracts other ants. From this prediction she expresses its function, but maintains some confusion. This confusion is the affective state that accompanies her process of accommodation, that pushes her to account for greater and greater parts of the complex phenomenon. As she forms the concept, she operationalizes it to make conclusions about excessive aggregation of ants in large reinforcing groups caused by pheromone's attractive qualities categorizing them as "powerballs". She then explains, with here newly constructed theory, how the phenomena end through the dissipation of the chemical through air, like perfume.

This interaction also suggests an answer to our first question, how can we capture visitor's moment-to-moment sense-making? Moment-to-moment expressions stick together as they account for what Rebecca sees. She even connects the declarative knowledge we probe with. When they no longer helped her understand, she dropped the ideas. Like her idea of pheromone just being on or off, rather than a continuous variable where more concentration is lighter colored and more attractive. This process of pruning suggested that in future uses of CDM, we should set a heuristic where we say something like "if an idea isn't used for X minutes, we can drop it from the tree." As a result, we used a version of this heuristic in the second treatment. Thus, her knowledge is assimilating over time to accommodate to what she has seen. In other words, she is constructing an idea of the parts of the representation she at first is confused by, and forms trees of processes that account for ever greater complexity of action in the 
agent-based model. At times, the process looks like unstable concepts. However, as she gathers more evidence, the concepts become helpful, predictive theories, helping her learn how to see the model.

CDM is a useful way to document this change and stability. The interaction had two main effects that CDM demonstrates. First, through the process of playing in the openended environment Rebecca created a theory of how feedback, represented by pheromone trails, in the complex system leads to self-organization. Second, our analysis of Rebecca's use of Ant Adaptation demonstrates constructivist dialogue mapping's utility in tracking learning as concept elaboration. Ant Adaptation scaffolds her development of theory to see how trails work in the microworld. The process of discovery engaged her as she constructed this understanding of pheromone trails.

\section{Treatment Two:}

\section{Constructing a Strategy to play Ant Adaptation through Feedback}

While CDM can be used to track concepts as they develop, as in Rebecca's case, you can also use it to monitor what people know before and after an intervention. In this second use, researchers can code the changes, before and after. New additions are coded in red in this treatment. ${ }^{4}$ While playing in a large natural history museum with his brothers and sister, Thomas and his siblings were recruited to the study. Often times in open-ended learning environments, interactions are not individual. Instead a whole family can interact with the exhibit simultaneously. Thus, Thomas' case demonstrates what one user developed through interacting with the game and his siblings. This section addresses our third question: How do these knowledge structures shift over time, or remain stable emerging as theories explaining the context?

\section{Thomas Pre-Interview}

During the pre-interview, we established Thomas' prior understanding of ants through a semi-structured interview. As shown in Fig. 10, during the pre-questions he said ants carry 50x their weight. In response to probes about how ants control traffic, he offered the explanation that ants make physical paths, to control traffic, which he later rescinded after playing the game. Protocol questions on aggressive roles prompted Thomas to guess aggression simply increases an ant's likelihood of getting hurt or even killed - a claim he later amended:

Interviewer: Okay. And then imagine you're an ant. How do you think being aggressive affects your life?

Thomas: Uh, if you're aggressive, like, you- you're ... Uh, how do we explain

\footnotetext{
${ }^{4}$ While in this case we only present before and after, researchers could pictorially represent the changes at finer grain sizes to show more of the construction of concepts, and also set heuristics for when ideas no longer inhabit a CDM.
} 


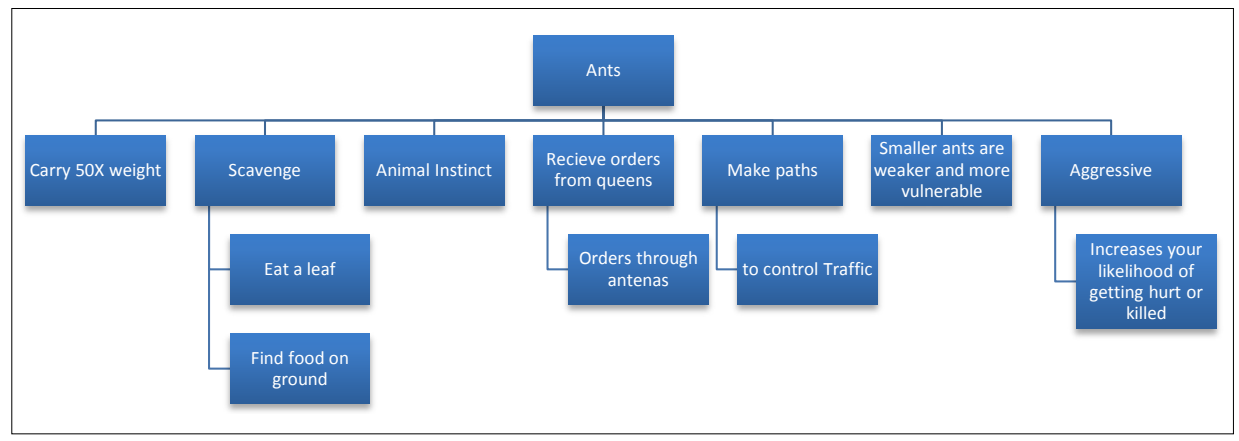

Fig. 10. Pre-play constructivist dialogue map of four players' understanding of ants. For instance, they think ants (entity) can carry 50 times their own weight (mechanism).

this? If you're aggressive, like, you-since you go for more things you have a greater risk of getting hurt or killed, I guess.

In response to questions about how ants know what to do, Thomas offered animal instinct, or, a command and control understanding when ants get orders through antenna and/or from their queen.

Interviewer: Okay. That's fair. And then, how do ants know what to do? So, you said they- they pick up leaves, or they scavenge, but how do they know to do that?

Thomas: Um, animal instincts.

Interviewer: Animal instincts.

Thomas: $\quad$ Or the queen tells them to, if there's a queen ant. We don't know.

Interviewer: So, what's the diff-How does the queen tell them to?

Thomas: It's something with their antennas.

Interviewer: Okay.

Thomas: I think. Additionally, he said that ants scavenge food from the ground or maybe eat leaves.

Thomas: $\quad$ Like, they can like go hunt for food. They can like, um, try like, get to some, like, maybe some food on the ground like in the city or like in a park, or they can just eat a leaf.

After we explained how the game worked, players broke into two teams, Thomas and Ed versus Mary and Sam. At the beginning, the younger Sam and Mary chose to have maximum-sized, not very aggressive ants (10\% aggressive). Thomas and Ed chose to have medium sized though not very aggressive ants ( $2 \%$ aggressive).

Near the beginning, players agreed through conversation on what strategies matter. Soon, Thomas informed the older Ed how to play: "add flowers close to the nest." From this we add a new ontological entity, flowers, into the group's constructivist dialogue map and put a mechanism 'close to the nest' under it because the players started planting 
flowers in close proximity. Notably, they did not mention flowers in the pre-interview, but also did not seem surprised by them. We think this is a case of constructing knowledge through action in the game world, as it is unlikely they knew that some types of Attini ants collect flowers for fungus farming. The players then established the connection between two complex systems ideas - the proximity of food and increasing ant population - through dynamic play with the model.

\section{Post- Interview}

Thomas seemed to develop an understanding of the feedback cycles inherent in Ant Adaptation. Thomas offered this understanding as the way to play the game.

Thomas: Yeah, you had to figure it out and the-you have to have some flowers, see, and then you put the chemicals and lead it to there, then they'll bring it back, and like, if you want to get rid of the chemicals you use the vinegar. So, um, you put some sunflowers down, then you get the chemicals and lead it to the sunflowers and if-if there's too much then the ants aren't getting the sunflowers and you-then they'll just like, then you use the vinegar and erase it. But if-if you just do one path that leads to the sunflowers it'll just get the energy and just keep going back and forth and back and forth. And that's how we got 21 [ants].

As shown in Fig. 11, in the post-test the players' concept maps became more elaborate. Thomas takes on a more cyclical understanding of the role of ants' paths to attract

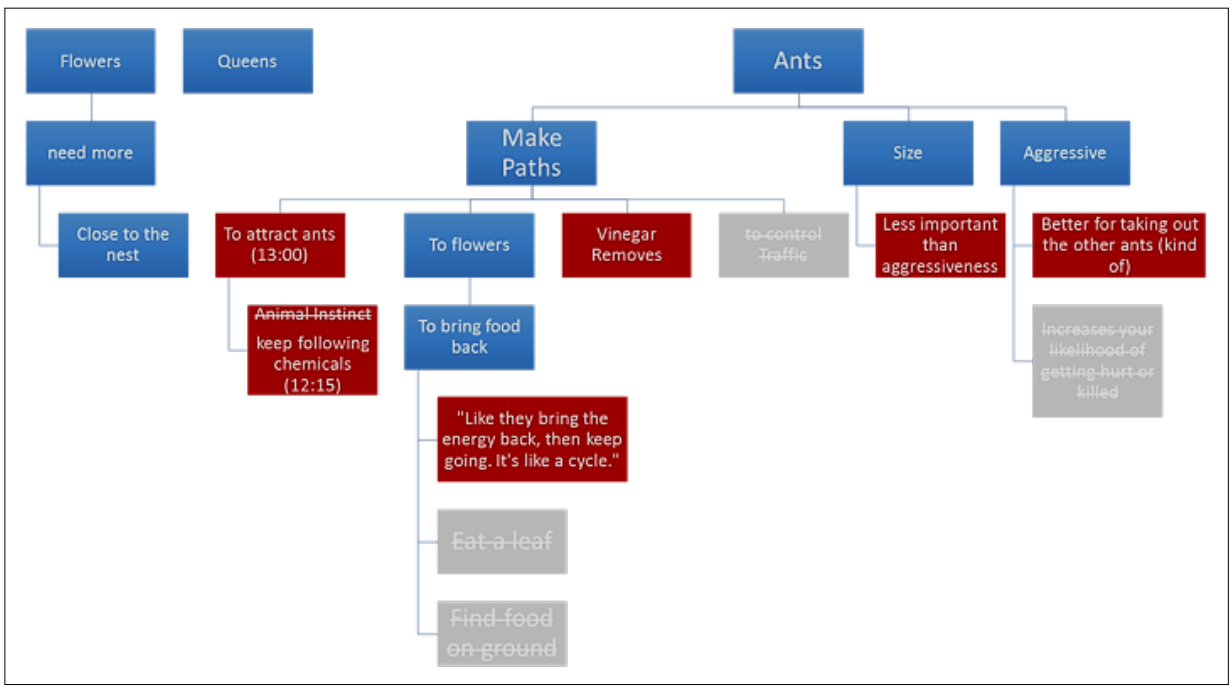

Fig. 11. Post-play constructivist dialogue map map of four players. Came to the cyclical understanding of pheromones in food foraging and a more contextual understanding of the role of adaptions utility. Red Boxes indicate elaboration. Grey ideas that were not mentioned again. 
each other to flowers. Thomas argued that ants follow chemicals to bring food to "get to 21 " ants. He also saw that sometimes ants can get trapped in their own chemicals or "white spots." He used vinegar to clear excess chemicals. One of the primary motivations of the learning environment was to teach that the simple rules of agents could lead to complex, social patterns that sustain a population of ants. Thomas's descriptions indicates he came to understand the impact of ants simple rules on complex social behaviors. Thomas leveraged this new understanding to use the macro-level effects of population size to lead his ants to victory by making predictions based in his theory of the agent based model's simple rules. Thomas employed complex systems thinking learned in the short interaction to reach his goal of maximizing population. He set this goal in communication with his teamate in the open-ended constructionist learning environment afforded by our design of Ant Adaptation.

Through play, Thomas learned that entities like ants have a mechanism such as laying trails to attract other ants to flowers in a cycle by recursively following the chemicals. He also realized that sometimes this process can lead ants astray as shown by his use of vinegar to redirect them out of deleterous local optima. He also constructed the concept that the food source's proximity to the colony increased the ant population by increasing food intake. After he stated as much, the other side started placing flowers close to their nest, indicating they also understood agents' actions led to the macro-level effect of population growth.

\section{Discussion}

We developed CDM (Martin, Horn and Wilensky, 2018; Martin and Wilensky 2018) to study learning in an informal environment (Martin, 2018) based on constructionist theory (Martin, Horn and Wilensky, 2019). Piaget presented a notion of knowledge that is constructed. Since he believed knowledge is constructed, Piaget invented the clinical interview to document how people construct these understandings during open-ended conversation and question-asking designed to illuminate the way the child thinks of or explains a phenomenon. The next step in this research for informatics is to automate it. This work poses some challenges, but will be feasible in the near-term and so is worth discussing here.

It is difficult to automatically transcribe what children say. But, the barriers are dropping. According to a report by RideOut Media (2017) Most American Children $(98 \%)$ are now in a home with a tablet or smartphone. These provide ubiquitous access to microphone, voice search enabled devices (Lovato \& Piper, 2019). Otter.ai, an AI powered transcription service, along with REV.com, are dropping the cost and increasing the accuracy of automated transcription. As this revolution takes place, the need to understand and identify key learning moments in children's speech will rise.

Consequently, we should focus on natural language processing to identify ontological entities, the functions they employ and their properties. In a naïve search, if all con- 
cepts had a specific name, this would be a search for nouns, the verbs those nouns take, and the adjectives and adverbs that that modify them. Unfortunately, language is less clear than that. Not all entities have names. Antecedents are not always clear. At the moment, bridging these connections is the work of humans.

Previous research, however, suggests that an automated ontological concept mapping can help us track theory development. For example, the OntoClean (Guarino, Nicola and Chris Welty, 2002) methodology supports the construction and evaluation of taxonomic relationships based on the use of a number of philosophical meta-properties - namely, unity, rigidity, identity and (notional) dependence - as well as on constraints limiting relationships that can be established between concepts (types, properties) tagged with these different meta-properties. It was the first attempt to formalize ontology for information systems. Moreover, Newsreader (Vossen et al., 2016) provides aggregation of information over massive amounts of online text to build stories that decision makers can use. In Newsreader there are four steps:

(1) Identification, that extracts what happened to whom, and where.

(2) DeDuplication, which makes sure that similar information across a corpus is available only once, while referencing each article referring to it.

(3) Aggregation show complementary articles across the corpus.

(4) Perspectivation, makes sure different viewpoints and perspectives in the corpus are traceable in the final narrative.

While the previous work with Newsreader and OntoClean examines large corpus understanding, we want to track how children develop their ideas in informal learning environments. They develop their ideas rapidly, and sometimes hold two conflicting notions simultaneously. CDM suggests potential for the context. The advantage of this approach is we can present the smallest parts of what we observe with large samples of transcript data. For instance, we can note when users first identify an unknown activity and then how they build out an understanding of the subprocesses of that task (Martin, Horn and Wilensky, 2018). Currently, we read the transcript to see how users construct such operational knowledge on the representations they see.

\section{Future Work}

As a purely qualitative method, CDM demonstrates learning as concept elaboration over time through the proxy of changes in speech (Leinhardt and Crowley, 1998). Through automating this process, in future work, we will scale the process, and thereby test our methods on larger n-samples of data. Mixed Human-Artificial Intelligence solutions, like Quantitative Ethnography (Shafer, 2017), Ncoder (Shafer et al., 2015) or DeepLabCut (Mathis, 2018 et al., 2018) are methods that we will use in the near term. These approaches mix researchers' hand-coding a small number of bits of text, that can scale to larger corpuses of text or behavior data using regular expressions or machine learning. 


\section{Conclusion}

The system of tracking players' conceptual development illustrated how their thinking changed throughout the interaction. Thomas learned that the chemical trails lead ants through a cycle that feeds the whole colony. He also learned that sometimes this process can lead ants astray, and how to intervene with vinegar in the self-organized system to optimized it. Meanwhile, Rebecca's knowledge emerged through play. Using CDM, we tracked how Rebecca created a theory of how feedback between ants in a colony leads to self-organization of food foraging. These two examples showed CDM's utility in tracking learning as concept elaboration through interaction with technology and a facilitator. The method highlights two parts of the theory:

(1) Elaboration of discussion improves understanding. And by tracking the paths of elaborations and its sometimes dual conceptions we can observe conservation of concepts in transcripts.

(2) Knowledge fluidly grows through action taken in a complex system. The dynamic interaction with the model enabled users to learn through mediation with the computer system, each other, and a facilitator. This sort of dialectic interaction could be scaled to other learning environments, and tracked through CDM.

The game facilitated its learning objectives by scaffolding theory development. When people engage part of a complex system, they attempt their best theories in real time, and received dynamic feedback from the computer and each other. The overly abundant data gets fit into a theory that people test in mediation with the machine and themselves and finds regularities and breaks in their system of thought.

The constructivist dialog mapping approach introduced in this paper was used to capture changes in a player's understanding of agents, functions and properties. We demonstrated the process of learning complex ant systems through playful interaction with our agent-based modelling game, Ant Adaptation. In future work, CDM could also be useful in tracking what people learn in other learning environments where they interact with peers, technology and teachers.

Elaboration of discussion improves understanding. Through the presentation of Thomas' case, we show that a player added to his understanding of ant colonies through the elaboration of discussion about a complex system. He started using vinegar to eliminate local optima where the ants got trapped. Simultaneously, he used the feedback of pheromone trails to organize his colony's foraging and adjust adaptations to changing circumstances.

Knowledge fluidly grew through action taken in the complex system. From Rebecca, we notice that her knowledge is fairly fluid - namely, she came up with theories on the fly. She took a while to decide on one, and it seems her notions were a bit more fixed and situational. Our research question was how users are building their knowledge when using the model of ant competition. She understands the rules of the behavior of individuals to make sense and meaning from agent-based models. Thus, we find this agentbased model a felicitous way for students to freely construct. Working with each other and mediated by the tabletop game, they build understanding of the complex systems 
processes by conserving change and forming operational concepts - like children growing up in a gas cloud.

Effortful problem-solving activity is the process of science, and that is the process constructivist dialogue mapping tracks. The CDM approach introduced in this paper was able to capture changes in a player's understanding of agents, functions and properties (entities' mechanisms), while they learned complex ant systems through playful interaction with our agent-based modelling game, Ant Adaptation. CDM captured the changes as utterances occurring during a short interaction. By analyzing changes in talk pre- and post- play, we found that a player learned about feedback, and employed that learning at multiple levels to maximize an ant population. The elaboration took place by forming and testing theories with Ant Adaption. This method could be used in other learning environments to inquire about the association between elaboration of talk about concept formation.

\section{Acknowledgements}

We would like to thank Paul Won, Gabby Anton, Bill Hoover, Rui Han and Melissa Perez for their feedback. We would like to thank Francisco López-Bermúndez for his illustrations. We also would like to thank the Center for Connected Learning and Computer Based Models, TIDAL, and TIILT labs for their feedback throughout the project, and the supportive Northwestern Community. Additionally, Marcelo Worsley and Emily Wang provided copious insight. Finally, we would like to thank the National Science Found (NSF Stem+C: Award \# 1842375) and the Multidisciplinary Program in Education Sciences (IES: Award \# R305B090009) for funding the project.

\section{References}

Ackermann, E. (2001). Piaget's Constructivism, Papert's Constructionism: What's the difference?

Ackerman, E. (1996). Perspective-Taking and Object Construction: Two Keys to Learning. In (Eds) Y. Kafai and M. Resnick Constructionism in Practice: Designing, Thinking and Learning in a Digital World. Lawrence Erlbaum, NJ. Clements, D.(1995) Playing with Computers, Playing with Ideas. Educational Psychology Review, 7(2), 203-207.

Anderson, J. R. (1976). Language, memory, and thought. Hillsdale, NJ. Eribaum.

Chi, M. T., \& Koeske, R. D. (1983). Network representation of a child's dinosaur knowledge. Developmental psychology, 19(1), 29.

Chi, M. T. H. (2008). Three types of conceptual change: Belief revision, mental model transformation, and categorical shift. In S. Vosniadou (Ed.), International handbook of research on conceptual change (pp. 61-82). Hillsdale, NJ: Erlbaum.

Chi, M. T., Hutchinson, J. E., \& Robin, A. F. (1989). How inferences about novel domain-related concepts can be constrained by structured knowledge. Merrill-Palmer Quarterly.

Clampet-Lundquist, S., Edin, K., Kling, J. R., \& Duncan, G. J. (2011). Moving teenagers out of high-risk neighborhoods: How girls fare better than boys. American Journal of Sociology

Collins, A. M., \& Loftus, E. F. (1975). A spreading-activation theory of semantic processing. Psychological review, 82(6), 407.

Collins, A. M., \& Quillian, M. R. (1969). Retrieval time from semantic memory. Journal of verbal learning and verbal behavior, $8(2), 240-247$. 
Conant, J. B. (1947). On Understanding Science -An Historical Approach.

Darner, R. (2019). How Can Educators Confront Science Denial?. Educational Researcher, 48(4), 229-238.

DiSessa, A. A., \& Cobb, P. (2004). Ontological innovation and the role of theory in design experiments. Journal of the Learning Sciences, 13(1), 77-103.

DiSessa, A. A. (1993). Toward an epistemology of physics. Cognition and instruction, 10(2-3), 105-225.

DiSessa, A. A. A. (2018). Knowledge in pieces: An evolving frame- work for understanding knowing and learning. In T. G. Amin \& O. Levrini (Eds.), Converging perspectives on conceptual change: Mapping an emerging paradigm in the learning sciences. (pp. 9-16). New York, NY: Routledge/Taylor \& Francis Group.

Duit, R., Treagust, D. F., \& Widodo, A. (2008). Teaching science for conceptual change: Theory and practice. In S. Vosniadou (Ed.), International handbook of research on conceptual change (pp. 629-646). Hillsdale, NJ: Erlbaum.

Edwards, L. D. (1995). Microworlds as representations. Computers and exploratory learning

Frank, A. (2011). About time: Cosmology and culture at the twilight of the big bang. Simon and Schuster.

Gobbo, C., \& Chi, M. T. H. (1986). How knowledge is structured and used by expert and novice

children. Cognitive Development, 1, 221-237.

Guarino, Nicola and Chris Welty. 2002. Evaluating Ontological Decisions with OntoClean. Communications of the ACM. 45(2):61-65. New York:ACM Press.

Hammer, D. (1996). Misconceptions or p-prims: How may alternative perspectives of cognitive structure influence instructional perceptions and intentions? Journal of the Learning Sciences, 5, 97-127.

Holbert, N., \& Wilensky, U. (2019). Designing Educational Video Games to Be Objects-to-Think-With. Journal of the Learning Sciences, 28(1). https://doi .org/10.1080/10508406.2018.1487302

Jackson, K. M., \& Trochim, W. M. (2002). Concept mapping as an alternative approach for the analysis of open-ended survey responses. Organizational Research Methods, 5(4), 307-336.

Kinchin, I. M. (2003). Effective teacher $\leftrightarrow$ student dialogue: A model from biological education. Journal of Biological Education, 37(3), 110-113.

Kinchin, I. M. (2014). Concept mapping as a learning tool in higher education: A critical analysis of recent reviews. The Journal of Continuing Higher Education, 62(1), 39-49.

Kuhn, T. S. (1962). The structure of scientific revolutions. Chicago and London.

Laurence, S., \& Margolis, E. (1999). Concepts and cognitive science. Concepts: core readings, 3, 81.

Martin, K. (2018). Constructivist Dialogue Mapping: Evaluating Learning During Play of Ant Adaptation, a Complex Interactive Tabletop Museum Game. 31st Annual Visitor Studies Association, 20.

Martin, K., Horn, M., \& Wilensky, U. (2018). Ant Adaptation: A complex interactive multitouch game about ants designed for museums. In Constructionism Conference.

Martin, K. and Wilensky, U. (2019). NetLogo Ant Adaptation model. http://ccl.northwestern.edu/ netlogo/models/AntAdaptation. Center for Connected Learning and Computer-Based Modeling, Northwestern University, Evanston, IL.

Martin, K., Horn, M., \& Wilensky, U. (2019). Prevalence of Direct and Emergent Schema and Change after Play. Informatics in Education, 18(1), 183.

Martin, K., Wang, E., Bain, C., \& Worsley, M. (2019). Computationally Augmented Ethnography: Emotion Tracking and Learning in Museum Games. In the Proceedings of International Conference of Quantitative Ethnography. Madison, Wisconsin.

Lovato, S. B., \& Piper, A. M. (2019). Young Children and Voice Search: What We Know From Human-Computer Interaction Research. Frontiers in Psychology, 10. https://doi .org/10.3389/fpsyg. 2019.00008

Leinhardt, G., \& Crowley, K. (1998). Museum learning as conversational elaboration: A proposal to capture, code, and analyze talk in museums. Report available at http://mlc. lrdc. pitt. edu/mlc.

Mathis, A., Mamidanna, P., Cury, K. M., Abe, T., Murthy, V. N., Mathis, M. W., \& Bethge, M. (2018). DeepLabCut: markerless pose estimation of user-defined body parts with deep learning (p. 1). Nature Publishing Group.

Medin, D. L., \& Rips, L. J. (2005) Concepts and categories: Memory, meaning, and metaphysics. In K. J. Holyoak \& R. G. Morrison, The Cambridge handbook of thinking and reasoning (pp. 37-72). New York: Cambridge University Press.

Miles, M. B., Huberman, A. M., \& Saldana, J. (2014). Qualitative data analysis. Sage.

Murphy, G. (2004). The big book of concepts. MIT press.

Norman, D. A., \& Rumelhart, D. E. (1975). Explorations in cognition.

Novak, J. D. (1990). Concept mapping: A useful tool for science education. Journal of research in science teaching, 27(10), 937-949. 
Novak, J. D., Bob Gowin, D., \& Johansen, G. T. (1983). The use of concept mapping and knowledge vee mapping with junior high school science students. Science Education, 67(5), 625-645.

Okada, A., \& Buckingham Shum, S. (2008). Evidence $\square$ based dialogue maps as a research tool to investigate the quality of school pupils' scientific argumentation. International Journal of Research \& Method in Education, 31(3), 291-315.

Okada, A. (2008). Scaffolding school pupils' scientific argumentation with evidence-based dialogue maps. In Knowledge Cartography (pp. 131-162). Springer, London.

Ochoa, X., \& Worsley, M. (2016). Augmenting Learning Analytics with Multimodal Sensory Data. Journal of Learning Analytics, 3(2), 213-219.

Papert, S. (1980). Mindstorms: Children, computers, and powerful ideas. Basic Books, Inc..

Papert, S. (1986). Constructionism: A new opportunity for elementary science education. A proposal to the National Science Foundation, Massachusetts Institute of Technology, Media Laboratory, Epistemology and Learning Group, Cambridge, Massachusetts

Papert, S., \& Harel, I. (1991). Situating constructionism. Constructionism, 36(2), 1-11.

Piaget, J. (1926). The language and thought of the child (Preface by E. Claparéde; translated by Marjorie and Ruth Gabain). London: Routledge and Kegan Paul.

Piaget, J. The child's conception of the world (1929). (translated by Joan and Andrew Tomlinson). London: Kegan Paul, Trench, Taubner, \& Company.

Piaget, J. (1952). The origins of intelligence in children. International Universities Press, Inc.

Pollner, M., \& Stein, J. (1996). Narrative mapping of social worlds: The voice of experience in Alcoholics Anonymous. Symbolic Interaction, 19(3), 203-223.

Posner, G. J., \& Gertzog, W. A. (1982). The clinical interview and the measurement of conceptual change. Science Education, 66(2), 195-209.

Posner, G. J., Strike, K. A., Hewson, P. W., \& Gertzog, W. A. (1982). Accommodation of a scientific conception: Toward a theory of conceptual change. Science Education, 66, 211-227.

Rideout, V. (2017). The Common Sense census: Media Use by Kids Age Zero to Eight Chap. San Francisco, CA. Common Sense Media.

Toulmin, S. E. (1972). The Collective Use and Evolution of Concepts. Princeton University Press. Vol 1.

Trochim, W. M. (1989). An introduction to concept mapping for planning and evaluation. Evaluation and program planning, 12(1), 1-16.

Vossen, P., Agerri, R., Aldabe, I., Cybulska, A., van Erp, M., Fokkens, A., ... \& Rospocher, M. (2016). NewsReader: Using knowledge resources in a cross-lingual reading machine to generate more knowledge from massive streams of news. Knowledge-Based Systems, 110, 60-85.

Wilensky, U. (1997). NetLogo Ants model. http://ccl.northwestern.edu/netlogo/models/Ants. Center for Connected Learning and Computer-Based Modeling, Northwestern University, Evanston, IL.

Wilensky, U. (1999). NetLogo. ccl.northwestern.edu/netlogo. Center for connected learning and computerbased modeling. Northwestern University, Evanston, IL.

Wilensky, U., \& Reisman, K. (2006). Thinking like a wolf, a sheep, or a firefly: Learning biology through constructing and testing computational theories - an embodied modeling approach. Cognition and Instruction, 24(2), 171-209.

K. Martin is a doctoral student at Northwestern University in Learning Sciences and a Multidisciplinary Program in Education Sciences fellow. He completed the Thomas Watson Fellowship, studying the simulation of ants through naturalistic observation in South America, the Middle East, and Africa. His research considers the pedagogical value of constructing agent-based models in complexity education, often times with ants. Some of his recent work has focused on restructuring history and creative writing classes through the use of digital environments. Find more about him at kitcmartin.com. 
M. Horn is an associate professor at Northwestern University with a joint appointment in Computer Science and the Learning Sciences. Mike runs the Tangible Interactive Design and Learning Lab. His research considers the intersection of human-computer interaction and learning, with a focus on thoughtful uses of emerging technologies in diverse learning settings. Some of his recent projects have included an investigation of multi-touch tabletops in natural history museums, and the use of tangible programming languages in kindergarten classrooms and science museums.

U. Wilensky, Lorraine H. Morton Professor of Learning Sciences, Computer Science and Complex Systems, is the founder and current director of the Center for Connected Learning and Computer-Based Modeling. He is also a faculty member in Cognitive Science, philosophy, the program in Technology and Social Behavior, the CIERA center and the Segal Design Center research council. He co-founded the Northwestern Institute on Complex Systems (NICO). He is the author of the NetLogo agent-based modeling software, which his lab actively maintains and improves. 